\title{
STRATEGI PENGUATAN KELOMPOK TANI NGUDI RAHARJO III DI DESA LEMBERANG, KECAMATAN SOKARAJA, KABUPATEN BANYUMAS
}

\section{STRATEGY FOR STRENGTHENING NGUDI RAHARJO III FARMERS GROUP IN LEMBERANG VILLAGE, SOKARAJA DISTRICT, BANYUMAS REGENCY}

\author{
Lutfi Zulkifli, Rifki Andi Novia \\ ${ }^{* 1}$ Jurusan Agribisnis, Fakultas Pertanian, \\ Universitas Jenderal Soedirman, Purwokerto, Jawa Tengah, Indonesia \\ E-mail: lutfizulkifli@unsoed.ac.id \\ (Diterima 10-05-2021; Disetujui 24-06-2021)
}

\begin{abstract}
ABSTRAK
Pada penelitian ini penulis akan mengusulkan beberapa strategi yang tepat untuk penguatan Kelompok Tani Ngudi Raharjo III di Desa Lemberang, Kecamatan Sokaraja, Kabupaten Banyumas, Jawa Tengah. Strategi yang diusulkan akan disusun berdasarkan analisis IFE dan EFE, SWOT serta analisis QSPM untuk mendapatkan strategi yang paling kuat dan dapat menjadi prioritas utama untuk dijalankan dalam penguatan pemberdayaan kelompok tani. Penelitian ini diharapkan dapat memberi solusi yang tepat untuk memberdayakan dan memaksimalkan potensi kelompok tani agar dapat dirasakan manfaatnya bagi seluruh anggota kelompok. Setelah mengidentifikasi faktor eksternal dan internal, analisis strategi yang berikutnya dilakukan adalah analisis strategi SWOT. Adapun strategi yang dihasilkan dari analisis SWOT bagi penguatan Kelompok Tani Ngudi Raharjo III, dilakukan analisis QSPM yang dapat menghasilkan strategi prioritas dari strategi yang ada. Setelah dilakukan analisis QSPM, pendampingan rutin oleh tenaga ahli pertanian dari Universitas Jenderal Soedirman merupakan strategi yang utama dan menjadi prioritas untuk dijalankan dengan Sum Total Attractiveness Scores (STAS) paling tinggi di antara strategi lainnya yaitu sebesar 6,91 .
\end{abstract}

Kata kunci: Pemberdayaan, SWOT, QSPM, Kelompok Tani, Kelembagaan

\begin{abstract}
In this research, the authors will propose several appropriate strategies for strengthening the Ngudi Raharjo III Farmer Group in Lemberang Village, Sokaraja District, Banyumas Regency, Central Java. The proposed strategy will be compiled based on IFE and EFE analysis, SWOT, and QSPM analysis to get the strongest strategy and can be a top priority to be implemented in strengthening the empowerment of farmer groups. This research is expected to provide the right solution to empower and maximize the potential of farmer groups so that the benefits can be felt for all group members. After identifying external and internal factors, the next strategy analysis is a SWOT strategy analysis. As the resulting strategy from the SWOT analysis for strengthening the Ngudi Raharjo III Farmer Group, a QSPM produced a priority strategy from the existing strategy. Assistance by agricultural experts from Jenderal Soedirman University was the main strategy and a priority to be carried out with the highest Sum Total Attractiveness Scores (STAS) among other strategies on QSPM Analysis, amounting to 6.91.
\end{abstract}

Keywords: Empowerment, SWOT, QSPM, Farmer Group, Institution

PENDAHULUAN

Kementerian Pertanian telah mendefinisikan bahwa kelompok tani adalah kumpulan petani/ peternak/ pekebun yang dibentuk atas dasar kesamaan kepentingan, kesamaan kondisi 
lingkungan (sosial, ekonomi, sumber daya) dan keakraban untuk meningkatkan dan mengembangkan usaha anggota tani di dalamnya.

\section{Hermantono \& Swatika (2011)}

menjelaskan bahwa tujuan dari dibentuknya kelompok tani adalah mengatasi masalah bersama dalam usahatani serta menguatkan posisi tawar petani, baik dalam pasar sarana maupun pasar produk pertanian. Di Desa Lemberang, Kecamatan Sokaraja, Banyumas telah terbentuk beberapa Kelompok Tani diantaranya adalah Kelompok Tani Ngudi Raharjo III. Kelompok Tani ini diketuai oleh Bapak Saptono dan telah memiliki susunan pengurus yang terdaftar di Dinas Pertanian. Namun, pada kenyataanya berdasarkan hasil wawancara yang dilakukan kepada pengurus dan anggota petani setempat, kelompok tani belum dapat dirasakan manfaatnya secara maksimal karena kurangnya partisipasi para anggota.

Tulandi et al (2018) menjelaskan bahwa partisipasi anggota tani dalam kelompok tani sangat penting untuk melaksanakan berbagai aktivitas ataupun program pertanian. Partisipasi dapat dibagi menjadi beberapa bentuk yaitu pembentukan keputusan, partisipasi dalam pembentukan pelaksanaan dan partisipasi dalam pembentukan evaluasi. Partisipasi anggota atau partisipasi petani merupakan keikutsertaan dari petani baik secara individu maupun secara kelompok pada bidang usaha pertanian dengan penuh kesadaran dan tanggung jawab. Berdasarkan penjelasan tersebut dapat diambil kesimpulan bahwa partisipasi petani akan sangat berpengaruh sekali terhadap pemberdayaan kelompok tani dan manfaatnya bagi semua pihak yang terkait.

Desa Lemberang mengalami beberapa kendala teknis dalam usaha taninya. Desa Lemberang berada di kawasan tanah yang cukup kering dan belum memilki saluran irigasi yang baik. Bagi sebagian petani padi di Desa Lemberang, saat Musim Tanam II (musim sadon) bukan merupakan saat yang tepat untuk menanam padi karena lahan persawahan diketahui mengalami kekurangan pasokan air dari sumber irigasi Bendungan Berem (BB) dan Bendungan Danayuda (BDY). Kondisi ini dipersulit dengan banyak bocor dan rusaknya saluran irigasi teknis yang membuat banyak terbuangnya air sebelum sampai ke lahan petani. Masalah teknis tersebut sebenarnya bisa didiskusikan dalam wadah musyawarah 
yang telah disediakan oleh kelompok tani untuk bersama mencari jalan keluar sehingga masalah dapat diatasi bersama.

Namun karena belum adanya pemberdayaan dan penguatan kelompok tani yang tepat, maka Kelompok Tani Ngudi Raharjo III belum berfungsi dengan baik sebagaimana sebuah kelembagaan kelompok tani bagi anggotanya. Susunan pengurus hanyalah ketua, sekretaris dan bendahara yang hanya digunakan sebagai kelengkapan administrasi. Pembagian tugas pun juga belum bisa dijalankan dengan maksimal karena belum lengkapnya pengurus seperti seksi-seksi yang membantu pengurus inti menjalankan kelembagaan kelompok tani. Rapat dan pertemuan kelompok tani juga belum dilakukan dengan rutin dan terjadwal, padahal kegiatan ini dapat menjadi sarana tukar informasi dan memecahkan permasalahan pertanian yang ada bersama-sama.

Peningkatan kemampuan kelompok tani dalam pemberdayaan kelompok tani mencakup beberapa hal: (1) memahami kelemahan, potensi, tantangan dan peluang kelompok, (2) memilih berbagai alternatif yang ada dengan bertukar informasi dan masukan untuk mengatasi masalah yang dihadapi, dan (3) menyelenggarakan kehidupan berkelompok dan bermasyarakat yang selaras dengan lingkungan berkesinambungan (Hermanto dan Swastika, 2011). Pada penelitian ini penulis akan mengusulkan beberapa strategi yang tepat untuk penguatan Kelompok Tani Ngudi Raharjo III. Strategi yang diusulkan akan disusun berdasarkan analisis IFE dan EFE, SWOT serta analisis QSPM untuk mendapatkan strategi yang paling kuat dan dapat menjadi prioritas utama untuk dijalankan dalam penguatan pemberdayaan kelompok tani. Penelitian ini diharapkan dapat memberi solusi yang tepat untuk memberdayakan dan memaksimalkan potensi kelompok tani agar dapat dirasakan manfaatnya bagi seluruh anggota kelompok.

\section{METODE PENELITIAN}

Penelitian ini dilakukan di Desa Lemberang, Kecamatan Sokaraja, Kabupaten Banyumas dengan objek penelitian yaitu Kelompok Tani Ngudi Raharjo III. Analisa data dilakukan di Fakultas Pertanian Universitas Jenderal Soedirman. Batasan masalah pada penelitian ini hanya membahas mengenai faktor eksternal dan internal kelompok tani yang didapatkan melalui wawancara dengan pengurus kelompok tani dan 
anggota kelompok tani. Responden dipilih melalui metode purposive yaitu pengurus dan anggota kelompok tani dimana responden dianggap mengetahui faktor internal dan eksternal yang ada dalam kelompok tani. Analisis Data Penyusunan strategi bagi penguatan pemberdayaan kelompok tani akan menggunakan metode SWOT dan Quantitative Strategic Planning Matrix (QSPM).

\section{HASIL DAN PEMBAHASAN}

\section{A. Identifikasi Faktor Internal dan Eksternal}

1. Identifikasi Faktor Internal

Berdasarkan faktor internal, dapat diidentifikasi kelemahan dan kekuatan yang dimiliki kelompok tani. Adapun faktor internal tersebut adalah sebagai berikut:

a. Kekuatan (Strength)

1) Pengetahuan yang baik tentang budidaya padi

Anggota Kelompok Tani Ngudi Raharjo III terdiri atas petani-petani yang telah puluhan tahun berpengalaman dalam bercocok tanam padi. Pengalaman ini memberikan banyak pelajaran dan pengetahuan aplikatif yang baik bagi para anggota kelompok tani.

2) Telah terbentuknya kelompok tani
Kelompok Tani Ngudi Raharjo III yang telah cukup lama terbentuk memberikan dampak positif karena pondasi utama dalam kelembagaan sudah dapat terbangun dengan baik.

3) Mendapat bantuan benih INPAGO

Kelompok Tani Ngudi Raharjo III telah mendapat bantuan benih INPAGO dari Fakultas Pertanian Universitas Jenderal Soedirman. Bantuan ini sangat bermanfaat sekali bagi kelompok tani, karena benih INPAGO yang memiliki keunggulan untuk tumbuh pada lahan yang kering dapat menjadi solusi bagi Kelompok Tani Ngudi Raharjo III yang memiliki masalah pada kurangnya pasokan air dan kekeringan lahan.

4) Sarana dan prasarana milik kelompok $\operatorname{tani}$

Kelompok Tani Ngudi Raharjo III memiliki sarana dan prasarana yang cukup menunjang kegiatan sosial dan pertanian anggotanya. Hal ini dapat dilihat dari adanya tempat pertemuan untuk menyelenggarakan rapat dan acara rutin lainnya, juga adanya alat-alat pertanian seperti traktor, penyemprot pestisida dan lain sebagainya.

b. Kelemahan (Weaknesses)

1) Kurangnya pemahaman petani terhadap teknologi tepat guna 
Anggota Kelompok Tani Ngudi Raharjo III sebagian besar belum bisa memanfaatkan teknologi dengan tepat guna. Hal ini ditunjukkan dari belum sesuainya takaran jumlah pupuk yang telah disarankan untuk diberikan kepada tanaman padi. Petani cenderung memberikan pupuk dalam jumlah yang melebihi takaran seharusnya, padahal lebihnya takaran ini dapat menyebabkan batang tanaman padi tidak kuat dan tumbang.

2) Pembukuan administrasi belum lengkap

Kegiatan pembukuan pada Kelompok Tani Ngudi Raharjo III diharapkan dapat membantu proses dokumentasi dan pencatatan berbagai macam atribut yang dibutuhkan dalam proses administrasi kegiatan internal dan eksternal kelompok tani.

3) Kurangnya kelengkapan administrasi dalam organisasi kelompok tani

Terhambatnya proses kelengkapan administrasi pada Kelompok Tani Ngudi Raharjo III menyebabkan banyak kekurangan yang terjadi pada proses pendataan anggota, yang juga dapat menghambat perencanaan kegiatan atau pendistribusian bantuan yang akan dilakukan oleh kelompok tani.
4) Belum maksimalnya pembagian tugas dalam kelompok tani

Pendelegasian tugas pada kelompok tani sangat penting untuk dapat dilakukan dengan efisien dan maksimal, karena banyaknya kegiatan dan tugas yang dijalankan oleh Kelompok Tani Ngudi Raharjo III membutuhkan tanggung jawab khusus dari masingmasing bagian yang harus dijalankan secara bersama-sama dengan fungsi pekerjaan yang berbeda-beda satu sama lain.

5) Kurangnya pertemuan rutin dalam kelompok tani

Kurangnya pertemuan rutin yang diadakan Kelompok Tani Ngudi Raharjo III dapat menghambat kegiatan yang dijalankan oleh kelompok tani. Karena kurangnya pertemuan rutin, banyak terjadi kesalahan dalam komunikasi yang dialami oleh anggota kelompok tani. Selain itu, pendistribusian informasi dan pemecahan masalah yang sedang dihadapi secara tepat dan lengkap juga dapat terganggu karena anggota yang tidak rutin bertemu secara langsung.

6) Kurangnya pemahaman petani terhadap pentingnya partisipasi dalam kelompok tani

Banyak anggota Kelompok Tani Ngudi Raharjo III yang tidak sadar akan 
pentingnya partisipasi aktif dalam kelompok tani. Hal ini disebabkan oleh anggota kelompok tani merasa belum maksimalnya manfaat yang didapatkan dari keikutsertaan dirinya bergabung dalam kelompok tani.

2. Identifikasi Faktor Eksternal

a. Peluang (Opportunities)

1) Permintaan beras cenderung meningkat

Beras adalah komoditas utama yang dibutuhkan masyarakat Indonesia sebagai bahan makanan pokok, hal ini menjadi keunggulan bagi Kelompok Tani Ngudi Raharjo III yang mayoritas anggotanya bercocok tanam padi. Semakin tingginya jumlah penduduk semakin meningkat pula kebutuhan makanan pokok, maka dari itu permintaan beras akan semakin bertambah.

2) Dekat dengan tenaga ahli pertanian dari Universitas Jenderal Soedirman

Kelompok Tani Ngudi Raharjo III terletak di Desa Lemberang, Kecamatan Sokaraja, Kabupaten Banyumas, Purwokerto. Dimana, lokasi ini dekat dengan Fakultas Pertanian Univeristas Jenderal Soedirman yang banyak melakukan kegiatan pengabdian masyarakat bagi petani setempat untuk membantu memajukan bidang pertanian berbasis kearifan lokal yang berkelanjutan.

3) Tingkat pendidikan masyarakat yang meningkat

Di era globalisasi ini, informasi sangat mudah diakses dari manapun dan oleh siapa pun. Hal ini tentunya menjadi salah satu peluang bagi anggota Kelompok Tani Ngudi Raharjo III karena banyak informasi dan ilmu yang mudah dipelajari dari berbagai sumber sehingga dapat meningkatkan wawasan anggota kelompok tani sendiri.

b. Ancaman (Threats)

1) Minimnya sumber daya manusia

Di Desa Lemberang tepatnya pada Kelompok Tani Ngudi Raharjo III, umumnya generasi muda sudah mulai tidak memiliki motivasi untuk menjadi petani dan beralih ke profesi lain. Hal ini berdampak pada kurangnya sumberdaya manusia muda yang aktif dan produktif pada anggota kelompok tani karena dibutuhkan banyak tenaga muda produktif untuk menjalankan kegiatan di Kelompok Tani Ngudi Raharjo III.

2) Kurangnya pasokan air

Desa Lemberang memiliki sumberdaya lahan yang kering dan para petani mengalami beberapa kendala teknis dalam usaha taninya. Desa Lembereng berada di kawasan tanah yang 
cukup kering dan belum memilki saluran irigasi yang baik.

3) Irigasi yang belum memadai

Petani di Desa Lemberang mengalami kekurangan pasokan air dari sumber irigasi Bendungan Berem (BB) dan Bendungan Danayuda (BDY). Kondisi ini dipersulit dengan banyak bocor dan rusaknya saluran irigasi teknis yang membuat banyak terbuangnya air sebelum sampai ke lahan petani.

4) Belum adanya teknologi benih yang sesuai

Kondisi lahan yang kering dan sistim irigasi yang belum memadai menuntut para petani untuk menemukan solusi yang tepat, salah satunya teknologi benih yang sesuai. Teknologi benih ini diharapkan dapat memberikan benih yang kuat tumbuh dalam kondisi seperti yang dialami para petani di Desa Lemberang.

5) Kekeringan lahan

Desa Lemberang memilki topografi lahan yang kering dan curah hujan yang minim. Hal ini juga menyulitkan petani karena petani masih harus dihadapkan dengan masalah lain seperti kurangnya pasokan air dan sistim irigasi yang belum memadai. Padahal, komoditas padi yang menjadi komoditas utama bagi para petani di Desa Lemberang membutuhkan pasokan air yang cukup dan tanah yang lembab agar bisa tumbuh dengan maksimal.

\section{B. Penetapan Alternatif Strategi}

1. Analisis Matriks IFE

Analisis Matriks IFE digunakan sebagai alat untuk menentukan faktorfaktor kelemahan dan kekuatan yang dimiliki oleh Kelompok Tani Ngudi Raharjo III. Hal ini selaras dengan penelitian Erawati et al (2018) bahwa pengidentifikasian faktor strategis internal memiliki pengaruh terhadap strategi pengembangan yang terdiri atas kekuatan dan kelemahan. Pada analisis Matriks IFE dilakukan pemberian bobot dan peringkat terhadap faktor-faktor strategi internal.

Berdasarkan hasil Analisis Matriks IFE pada Tabel 1, dapat terlihat bahwa skor total dari analisis faktor internal berjumlah 2,1. Angka ini menunjukan bahwa faktor internal pada Kelompok Tani Ngudi Raharjo III berada di tengahtengah peringkat skor total 1-4 $(2,1)$ yang mengindikasikan bahwa kekuatan internal masih cukup berada di rata-rata. Namun angka ini perlu harus ditingkatkan demi menguatkan kekuatan internal kelompok tani, karena dari kekuatan internal ini kelompok tani memiliki pondasi kelembagaan yang kuat 


\section{STRATEGI PENGUATAN KELOMPOK TANI NGUDI RAHARJO III DI DESA LEMBERANG, \\ KECAMATAN SOKARAJA, KABUPATEN BANYUMAS \\ Lutfi Zulkifli, Rifki Andi Novia}

dalam menjalankan kegiatan dan anggotanya.

mencapai tujuan untuk mensejahterakan

Tabel 1. Hasil Evaluasi Faktor Internal (IFE)

\begin{tabular}{clccc}
\hline \multicolumn{1}{c}{ Ancaman } & Bobot & Peringkat & $\begin{array}{c}\text { Skor } \\
\text { Bobot }\end{array}$ \\
\hline 1 & Kurangnya pemahaman petani terhadap teknologi tepat guna & 0,04 & 3 & 0,12 \\
2 & Pembukuan administrasi belum lengkap & 0,09 & 2 & 0,18 \\
3 & Kurangngnya kelengkapan administrasi dalam organisasi & $\mathbf{0 , 1}$ & $\mathbf{2}$ & $\mathbf{0 , 2}$ \\
& kelompok tani & & \\
4 & Belum maksimalnya pembagian tugas dalam kelompok tani & 0,09 & 2 & 0,18 \\
5 & Kurangnya pertemuan rutin dalam kelompok tani & $\mathbf{0 , 2}$ & $\mathbf{1}$ & $\mathbf{0 , 2}$ \\
6 & Kurangnya pemahaman petani terhadap pentingnya & $\mathbf{0 , 2}$ & $\mathbf{1}$ & $\mathbf{0 , 2}$ \\
& partisipasi dalam kelompok tani & & & \\
\hline No & & & 0,1 & 0,3 \\
\hline 1 & Pengetahuan yang baik tentang budidaya padi & 0,05 & 4 & 0,2 \\
2 & Telah terbentuknya kelompok tani & 0,03 & 4 & 0,12 \\
3 & Mendapat bantuan benih INPAGO & $\mathbf{0 , 1}$ & $\mathbf{4}$ & $\mathbf{0 , 4}$ \\
4 & Sarana dan prasarana milik kelompok tani & Total & $\mathbf{1}$ & $\mathbf{2 , 1}$ \\
\hline
\end{tabular}

Sumber: Analisis Data Primer (2021)

Berdasarkan Tabel 1 juga dapat dilihat bahwa pada faktor kelemahan, kurangngnya kelengkapan administrasi dalam organisasi kelompok tani, tidak adanya pertemuan rutin dalam kelompok tani, kurangnya pemahaman petani terhadap pentingnya partisipasi dalam kelompok tani memiliki skor bobot masing-masing sebesar 0,2. Hal ini menunjukan bahwa belum lengkapnya administrasi dan kurangnya partisipasi aktif dan pertemuan rutin bagi Kelompok Tani Ngudi Raharjo III merupakan kelemahan yang harus diprioritaskan penanggulangannya agar tidak semakin menghambat kegiatan yang dijalankan oleh kelompok tani. Didukung dalam penelitian Yani (2013) yang menyatakan bahwa anggota kelompok seyogyanya harus dilibatkan dalam penyusunan perencanaan program pertanian, karena para anggota dapat memberikan masukan mengenai kebutuhan dan masalah yang sedang dihadapi anggota kelompk, serta musyawarah bagaimana penyelesaiannya dan tujuan apa yang hendak dicapai bersama.

Terdapat 2 kekuatan besar yang dimiliki oleh Kelompok Tani Ngudi Raharjo III berdasarkan Tabel 1, yaitu sarana dan prasarana milik kelompok tani dengan skor bobot tertinggi sebesar 0,4 dan pengetahuan yang baik tentang budidaya padi dengan skor bobot kedua terbesar yaitu 0,3. Kedua kekuatan ini menjadi modal yang sangat baik bagi kelompok tani dalam menjalankan kegiatannya. Sarana prasarana yang telah 
dimiliki oleh Kelompok Tani Ngudi Raharjo III dapat dimanfaatkan dengan sebaik-baiknya oleh para anggota untuk membantu melakukan usaha pertanian dan juga mendukung kegiatan kelompok tani. Petani yang telah memiliki pengetahuan yang baik dalam budidaya padi juga menjadi kekuatan yang penting dan harus dipertahankan serta ditingkatkan, karena dapat menunjang kegiatan budidaya yang dijalankan sehari-hari oleh petani sheingga dapat membantu peningkatan produktivitas padi dan kesejahteraan petani.

2. Analisis Matriks Evaluasi Faktor Eksternal (EFE)

Faktor eksternal merupakan faktor yang juga berpengaruh dalam penyusunan strategi bagi penguatan kelembagaan pada Kelompok Tani Ngudi Raharjo III. Menurut David (2011), faktor eksternal meliputi evaluasi informasi ekonomi, sosial, lingkungan, budaya, demografis, politik, hukum, teknologi dan kompetitif. Ningsih \& Hamamah (2017) menyatakan bahwa matriks EFE digunakan untuk mengetahui bagaimana besarnya pengaruh faktor eksternal terhadap suatu kondisi. Hasil penjumlahan total dari perkalian bobot dan peringkat masingmasing faktor eksternal adalah hasil skor bobot total yang menunjukkan bagaimana kuatnya pengaruh faktor eksternal bagi kelompok tani.

Tabel 2. Analisis Matriks EFE

\begin{tabular}{clccc}
\hline No & \multicolumn{1}{c}{ Ancaman } & Bobot & Peringkat & $\begin{array}{c}\text { Skor } \\
\text { Bobot }\end{array}$ \\
\hline 1 & Minimnya sumber daya manusia & 0,1 & 2 & 0,2 \\
2 & Kurangnya pasokan air & 0,05 & 3 & 0,15 \\
3 & Irigasi yang belum memadai & 0,04 & 3 & 0,12 \\
4 & Belum adanya teknologi benih yang sesuai & 0,05 & 3 & 0,15 \\
5 & Kekeringan lahan $\quad$ Peluang & $\mathbf{0 , 0 6}$ & $\mathbf{4}$ & $\mathbf{0 , 2 4}$ \\
\hline No & \multicolumn{1}{c}{ Permintaan beras cenderung meningkat } & 0,2 & \\
\hline 1 & Pekat dengan tenaga ahli pertanian dari Universitas & $\mathbf{0 , 4}$ & $\mathbf{4}$ & $\mathbf{1 , 6}$ \\
2 & Jenderal Soedirman $\quad 0,1$ & 2 & 0,2 \\
3 & Tingkat pendidikan masyarakat yang meningkat & $\mathbf{1}$ & & $\mathbf{3 , 4 6}$ \\
\hline
\end{tabular}

Sumber: Analisis Data Primer (2021)

Skor bobot total pada Tabel 2 menggambarkan bahwa dari skala peringkat 1-4, Kelompok Tani Ngudi Raharjo III memiliki skor 3,46 yang telah mendekati peringkat tertinggi yaitu 4, dimana hal ini berarti kelompok tani telah memiliki peluang-peluang kuat untuk menghadapi ancaman pada kondisi eksternal. Pada data yang telah dipaparkan di Tabel 2, kekeringan lahan 
memiliki skor bobot tertinggi yaitu 0,24. Hal ini dapat disimpulkan bahwa faktor ancaman kekeringan lahan merupakan ancaman yang paling serius yang tengah dihadapi oleh kelompok tani. Selaras dengan apa yang telah dijabarkan oleh anggota kelompok tani, kondisi demografis desa Lemberang memang memiliki curah hujan yang cenederung rendah dan tanah yang kering. Lahan yang kering memang menjadi hambatan utama bagi petani di desa Lemberang, karena komoditas padi yang dibudidayakan membutuhkan banyak pasokan air dari tanah dan sumber irigasi juga curah hujan agar dapat tumbuh dengan maksimal.

Pada faktor eksternal lainnya, peluang Kelompok Tani Ngudi Raharjo III yang dekat dengan tenaga ahli pertanian dari Universitas Jenderal Soedirman merupakan peluang terkuat dalam Analisis Faktor EFE dengan skor bobot sebesar 1,6. Tenaga ahli pertanian dari Universitas Jenderal Soedirman diharapkan dapat memberi banyak informasi, ilmu dan pengalaman terkait teknologi maupun cara budidaya yang baik untuk petani dalam bidang penyuluhan pertanian di desa Lemberang. Ujung tombak dalam pembangunan pertanian tidak lepas dari peran penyuluh pertanian. Keberhasilan penyuluhan akan didapatkan dengan baiknya kualitas dan kauntitas tenaga ahli profesioanal dalam bidang penyuluhan pertanian (Vintarno et al, 2019).

\section{Analisis SWOT}

Setelah melakukan identifikasi matriks EFE dan IFE serta mendapatkan faktor eksternal dan internal pada Kelompok Tani Ngudi Raharjo III, maka selanjutnya adalah menetapkan pemilihan strategi yang tepat dari kekuatan, kelemahan, peluang dan ancaman yang sudah teridentifikasi. Menurut Erniati et al (2020), pola matriks SWOT untuk menyusun alat alternatif strategi dimulai dengan mengoptimalkan kekuatan dan memanfaatkan peluang (SO), dilanjutkan dengan menggunakan kesempatan eksternal untuk meminimalisir dampak dari kelemahan (WO), menghadapi ancaman dengan menggunakan kekuatan (ST), serta menggabungkan kelemahan dan ancaman (WT). Pada Tabel 3 di bawah ini menunjukkan analisis penetapan strategi dengan menggunakan metode SWOT untuk penguatan kelembagaan Kelompok Tani Ngudi Raharjo III. 
Tabel 3. Analisis SWOT

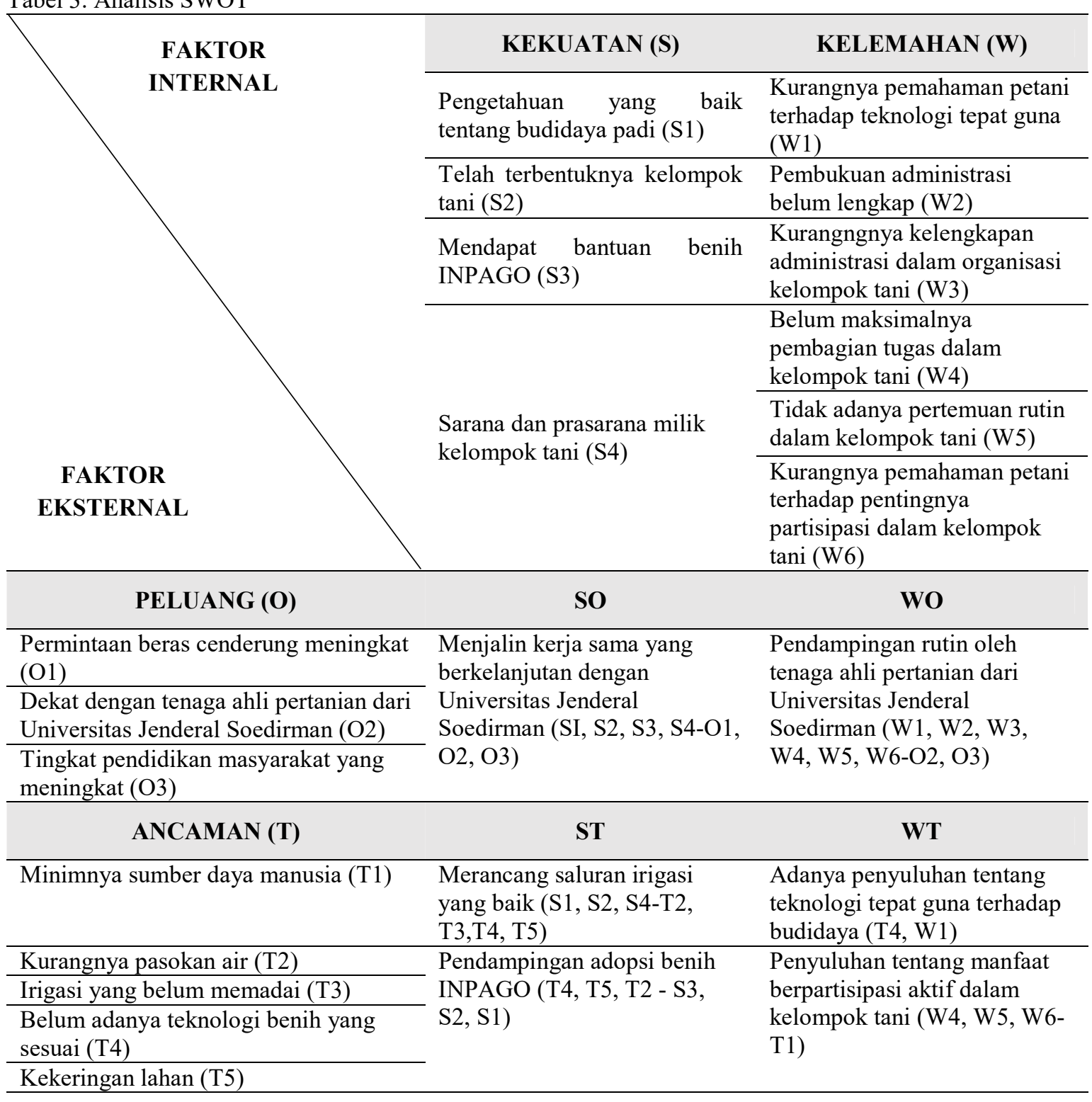

Berdasarkan Tabel 3, dihasilkan beberapa strategi dari analisis SWOT yang dapat digunakan untuk menguatkan Kelompok Tani Ngudi Raharjo III. Faktor kekuatan dan peluang dapat dimaksimalkan (SO) yang akan menghasilkan strategi Menjalin kerja sama yang berkelanjutan dengan Universitas Jenderal Soedirman. Kerja sama ini diharapkan akan terus berlanjut ke depannya sebagai bentuk pendampingan rutin dari tenaga ahli pertanian Universitas Jenderal Soedirman bagi kelompok tani yang juga merupakan strategi dari hasil pengoptimalan peluang yang digunakan untuk meminimalisir kelemahan kelompok tani (WO).

Kekuatan yang dimiliki kelompok tani juga dapat dimanfaatkan untuk meminimalisir ancaman dari faktor 
eksternal (ST) sehingga dapat menghasilkan dua alternatif strategi, yaitu perancangan saluran irigasi yang baik dan pendampingan adopsi benih. Saluran irigasi yang baik akan menjadi solusi bagi masalah kekeringan dan kurangnya pasokan air yang dialami petani di Desa Lemberang, sedangkan pendampingan adopsi benih akan membantu petani dalam proses pengaplikasian bantuan benih INPAGO bagi budidaya padi petani di Desa Lemberang. Perumusan strategi penguatan kelompok tani juga dapat diambil dari pencocokan antara kelemahan dan ancaman eksternal (WT), yaitu adanya penyuluhan tentang teknologi tepat guna terhadap budidaya dan penyuluhan tentang manfaat berpartisipasi aktif dalam kelompok tani. Penyuluhan pertanian diharapkan dapat menjadi jembatan bagi anggota Kelompok Tani Ngudi Raharjo III dalam proses penguatan kelembagaan dan mencapai kesejahteraan bersama. Menurut Rahmawati et al (2019), perubahan perilaku petani dalam berusahatani adalah dampak dari peran kinerja penyuluh yang baik sebagai motivator, edukator, fasilitator dan dinamisator.
4. Analisis QSPM (Quantitative Strategic Planning Matrix)

Setelah mengetahui strategi alternatif dari analisis SWOT, kemudian strategi tersebut dapat dianalisis kembali untuk dilihat strategi yang akan menjadi prioritas. Analisis yang digunakan adalah analisis QSPM, dimana menurut Paginian et al (2021) analisis QSPM adalah alat analisis perumusan strategi untuk tahap terakhir dalam sebuah penelitian. Variasi strategi yang dipilih dari matriks SWOT dapat ditetapkan daya tarik relatif nya dengan QSPM dan akan didapatkan strategi utama yang paling tepat untuk dijalankan saat ini. Berikut data hasil analisis matriks QSPM yang disajikan dalam Tabel 4.

Berdasarkan Tabel 4, dapat dilihat bahwa strategi yang memiliki nilai Sum Total Attractiveness Scores (STAS) paling tinggi di antara strategi lainnya yaitu sebesar 6,91 adalah strategi pendampingan rutin oleh tenaga ahli pertanian dari Universitas Jenderal Soedirman Hal ini menunjukkan bahwa strategi prioritas yang dibutuhkan oleh Kelompok Tani Ngudi Raharjo dalam menguatkan kelembagaanya adalah dengan mendapatkan pendampingan rutin oleh tenaga ahli pertanian dari Universitas Jenderal Soedirman. 
Tabel 4. Hasil Analisis Matriks QSPM

\begin{tabular}{clcc}
\hline No. & \multicolumn{1}{c}{ Strategi Alternatif } & Nilai STAS & Prioritas \\
\hline 1. & Menjalin kerja sama yang berkelanjutan dengan Universitas Jenderal & 5,52 & III \\
& Soedirman & 3,23 & VI \\
2. & Merancang saluran irigasi yang baik & 4,73 & IV \\
3. & Pendampingan adopsi benih INPAGO & $\mathbf{6 , 9 1}$ & I \\
4. & Pendampingan rutin oleh tenaga ahli pertanian dari Universitas & 4,18 & V \\
& Jenderal Soedirman & 5,93 & II \\
5. & Adanya penyuluhan tentang teknologi tepat guna terhadap budidaya & &
\end{tabular}

Sumber: Analisis Data Primer (2021)

\section{KESIMPULAN DAN SARAN}

Analisis strategi penguatan Kelompok Tani Ngudi Raharjo III di Desa Lemberang dimulai dari mengidentifikasi faktor eksternal dan internal yang menjadi kekuatan, kelemahan, peluang dan ancaman bagi penguatan kelompok tani. Setelah mengidentifikasi faktor eksternal dan internal, analisis strategi yang berikutnya dilakukan adalah analisis strategi SWOT. Adapun strategi yang dihasilkan dari analisis SWOT bagi penguatan Kelompok Tani Ngudi Raharjo adalah:

1. Menjalin kerja sama yang berkelanjutan dengan Universitas Jenderal Soedirman.

2. Pendampingan rutin oleh tenaga ahli pertanian dari Universitas Jenderal Soedirman.

3. Merancang saluran irigasi yang baik.

4. Adanya penyuluhan tentang teknologi tepat guna terhadap budidaya.
5. Pendampingan adopsi benih INPAGO.

6. Penyuluhan tentang manfaat berpartisipasi aktif dalam kelompok tani

Dari strategi tersebut, dilakukan analisis QSPM yang dapat menghasilkan strategi prioritas dari keenam strategi yang ada. Setelah dilakukan analisis QSPM, pendampingan rutin oleh tenaga ahli pertanian dari Universitas Jenderal Soedirman merupakan strategi yang utama dan menjadi prioritas untuk dijalankan dengan Sum Total Attractiveness Scores (STAS) paling tinggi di antara strategi lainnya yaitu sebesar 6,91.

Saran yang dapat diberikan adalah berdasarkan hasil analisis stretegi yang telah dilakukan, Fakultas Pertanian Universitas Jenderal Soedirman hendaknya terus mendukung pendampingan rutin dalam menguatkan kelembagaan pada Kelompok Tani Ngudi 
Raharjo III dengan skema berkelanjutan dan konsisten sehingga pendampingan ini tidak bersifat sementara melainkan dapat dijalankan dalam jangka waktu yang lebih panjang hingga tujuan dan kesejahteraan Kelompok Tani Ngudi Raharjo III tercapai. Penelitian selanjutnya diharapkan dapat dilakukan untuk mendukung pengembangan teoriteori baru dalam rangka menjalankan kegiatan aktif bagi penguatan kelembagan kelompok tani.

\section{DAFTAR PUSTAKA}

Hermanto \& Swatika, D.K.S. (2011). Penguatan Kelompok Tani: Langkah Awal Peningkatan Kesejahteraan Petani. Analisis Kebijakan Pertanian, 9(4): 371390.

Tulandi, C.K., Talumingan, C., \& Jocom, S.G. (2018). Partisipasi Anggota pada Kegiatan Kelompok Tani Mitra Jaya di Desa Mundung Kecamatan Tombatu Timur. AgriSosioEkonomi Unsrat, 14(3): 287296

Ginting, A. (2006). Perumusan Strategi Perusahaan PT X menggunakan Matriks Evaluasi Faktor. Jurnal Sistem Teknik Industri, 7(1): 1-5.

Yani, D.E., Pertiwi, R.P., Sigit, A. (2013). Partisipasi Anggota Kelompok Tani dalam Menganalisis Data Keadaan pada Usahatani Sayuran (Kelompok tani sayuran di Desa Margamekar, Kecamatan Pangalengan, Kabupaten Bandung). Jurnal
Matematika, Sains, dan Teknologi, 14(1): 62-72.

Erawati, N.M.Y., Suamba,K., Astiti, N.W.S. (2018). Strategi Pengembangan Usaha Pupuk Organik pada UD Darma Puri Farm di Desa Tangkas, Kecamatan Klungkung, Kabupaten Klungkung. Jurnal Manajemen Agribisnis, 6(2): 69-82.

Ningsih, K., \& Hamamah, H. (2014). Matrix Internal Factor Evaluation (IFE) dan External Factor Evaluation (EFE) Buah Naga Organik (Hylocereus Undatus). Agromix, 5(1): 12-21

David, F.R. (2011). (Strategic Management) Manajemen Strategis Konsep. Penerbit Salemba Empat, Jakarta.

Vintarno, J., Sugandi, Y.S., Adiwisastra, J. (2019). Perkembangan Penyuluhan Pertanian dalam Mendukung Pertumbuhan Pertanian di Indonesia. Responsive, 1(3):9096.

Erniati, Solahudin, M., Lulung, P., Wardani, I.K. (2020). Aplikasi Metode Analisis SWOT untuk Merumuskan Strategi Pemanfaatan Mekanisasi Pertanian di Kabupaten Kapuas Hulu Provinsi Kalimantan Barat. Jurnal Ilmiah Rekayasa Pertanian dan Biosistem, 8(2): 219229.

Rahmawati, Baruwadi, M., Bahua, M.I. (2019). Peran Kinerja Penyuluh dan Efektivitas Pelaksanaan Penyuluhan pada Program Intensifikasi Jagung. Jurnal Sosial Ekonomi Pertanian, 15(1): 56-70

Paginian, E., Kurniati, D., Yusro, A.H.A. (2021). Strategi Peningkatan Kinerja Penyuluh Pertanian di Kabupaten Landak. Jurnal Sosial Ekonomi Pertanian dan Agribisnis (SEPA), 17(2): 135-142 